\title{
Exam delays throw residents' careers into limbo
}

- Cite as: CMAJ 2020 April 14;192:E413-4. doi: 10.1503/cmaj.1095858

Posted on cmajnews.com on March 23, 2020

Update: After the publication of this article, the Royal College of Physicians and Surgeons of Canada announced that graduating medical students will still be able to obtain an educational licence to enter residency and graduating residents will be eligible for temporary licences to continue working.

anada's resident doctors are preparing for major disruptions to their lives and careers from the deferral of licensing exams until the fall or beyond.

On March 20, the Royal College of Physicians and Surgeons of Canada announced that written licensing exams scheduled for the end of March and April, and the oral exams to follow, would be postponed until September 2020, given the current COVID-19 pandemic.

The decision was motivated at least partly by a desire to free up residents to provide clinical care during the pandemic. A letter from the Quebec health ministry, seen by CMAJ, asked the Royal College to delay exams until at least the end of May to ensure that residents were available to work.

Initially, the plan was to hold the exams in late April and May, but after consulting with provincial health ministries, universities, faculty and resident groups, it was decided to push them back to September, according to the Royal College. However, if fall exams threaten to conflict with the clinical response to the pandemic in Canada, the Royal College has said it will reassess. It has committed to giving residents at least six weeks' notice prior to exams.

"As the pandemic progresses, it is important to have all trained hands at the ready. Facilitating the full participation of residents in this response is important," the Royal College said in a letter to residents.

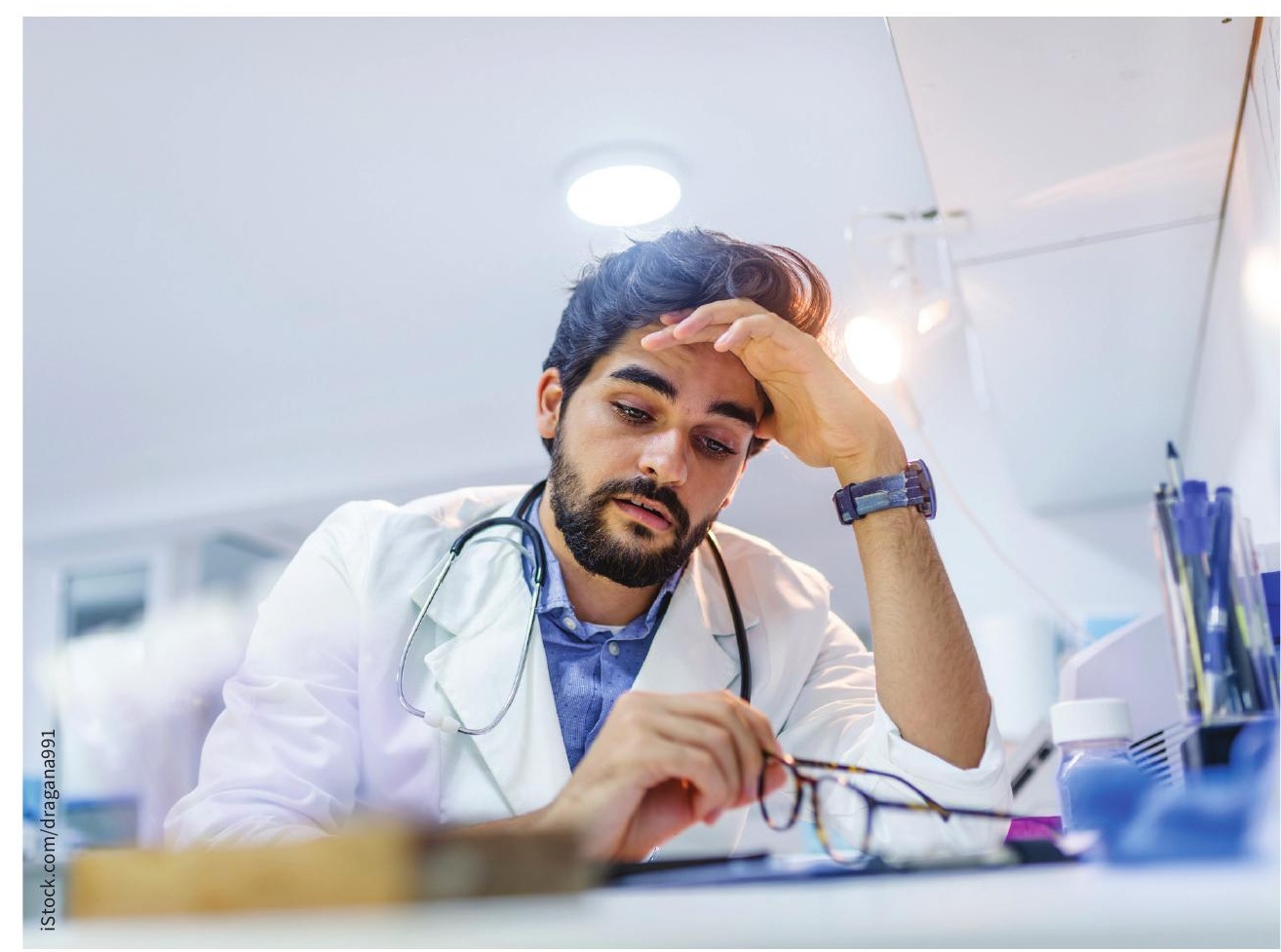

Resident doctors' personal and professional lives are up in the air until they can take licensing exams.

Many resident doctors reacted with shock to the announcement, said Dr. Emily Stewart, president of Resident Doctors of Canada. The association has received hundreds of emails from its members worried about the personal and professional impact of the delay. "People are understandably upset," she said. "Prepping for exams without a finish line is very stressful."

CMAJ spoke with several senior residents, all of whom asked to remain anonymous, about their concerns. Residents often make decisions about family planning and where they live based around the exam schedule and are now concerned about how the uncertainty will affect those plans. Some are due to give birth after the original exam date, or their partners are, and will now have to deal with caring for an infant while continuing to study and work.

The career impacts of delaying the exams also remain unclear. Some residents who planned to start a fellowship in July will likely be able to start it as planned, even if they have not yet written the exams, but those planning to start independent jobs are not sure what will happen if they do not have their licence to practise in time.

According to the Royal College, provincial licensing authorities have mechanisms to provide provisional and restricted licences in the event of delayed exams, but residents are concerned about the uncertainty that provisional licences will bring. 
Delays could also harm candidates' chances of success when the exams are eventually held. Many residents study in groups, particularly for the oral exam. Holding exams in the fall, after existing groups have dispersed across the country and residents are in jobs with no protected study time, will make it more difficult for candidates to prepare.

Residents are also unhappy with how the Royal College made and communicated the decision to delay the exams, with one describing the quantity and quality of information from the college as "appalling." The initial announcement to delay exams until April was made on Twitter, rather than in an official private email, and some residents are angry that they were not consulted in advance. They also feel that the concerns of residents are not being represented in ongoing discussions.

Several grassroots initiatives have sprung up in response to this perceived lack of consultation. A petition calling on the college to ensure doctors can take their exams on time attracted more than 6000 signatures, and a group of more than 750 senior residents has written a letter to the college laying out their concerns.

A group of more than 1100 doctors, led by Dr. John David Neary, a general internist in Hamilton, has written to the college asking for a special meeting on potential solutions to the exam issue. They suggest that instead of deferring the exams, the college should create a one-time path to certification for 2020 candidates. "These are extraordinary circumstances," said Neary. "We need to look beyond usual processes." Deferral shouldn't be contemplated, he argued.

The group suggests that the oral exams should be scrapped but the written exams could still take place at the original time in an electronic form or be replaced by an assessment of evaluations by program directors. As a last resort, they suggest simply certifying all residents rather than deferring the exams.
Other residents, while upset at the disruption, agree that the deferral was necessary. "This is a pandemic, the world is very different now," said one resident in Toronto, who was scheduled to write the exam in April. "How can you host an exam as a medical body while advocating social distancing for the rest of the public?"

Stewart says many residents are quickly coming to terms with the disruption and are working hard to ensure their patients get the best possible care during a stressful time for everyone. "Most residents have come to appreciate that these are unprecedented, highly unusual circumstances that evolve every day," she said. "Most people's anger has transitioned into an understanding that while exams are being hammered out their main focus is on helping with patient care, which I think just speaks to the type of people we have as doctors."

Brian Owens, St. Stephen, N.B. 